\title{
Performance Analysis of Power System Indices for Islanding Detection
}

\author{
Zubair Younas and Safdar Raza* \\ Department of Electrical Engineering, NFC Institute of Engineering \& Technology, Punjab, \\ Pakistan; zubairyounas41@yahoo.com, safdar.raza@nfciet.edu.pk
}

\begin{abstract}
Objective: In this work, a passive islanding detection technique based on performance analysis of power system indices has been proposed for a hybrid system. Method: The commonly used 12 different power system indices are analyzed on the basis of sensitivity/performance under all possible islanding and non-islanding scenarios, such as capacitor injection/ ejection, load increment/decrement, starting of induction motor, single and three phase faults. Findings: It has been found, based on performance analysis, that active power shows the highest capability to distinguish minute variations in the system. Subsequently, a passive technique, that utilizes active power as a discriminative feature, is proposed. Further, a protracted study is conducted to test the capability of the technique to discern the islanding and non-islanding scenarios of comparable signatures. Application/improvements: This technique presents high accuracy and zero impact on power quality. These characteristics make this technique appropriate for real-world operation.
\end{abstract}

Keywords: Power Indices, Islanding Detection, Performance Analysis, Distributed Generation, NDZ.

\section{Introduction}

The world is moving towards distributed energy resources (DERs) due to the prevailing global warming threat, a rapid decrease in world conventional energy resources and high transmission losses. These DERs are more reliable, cost-effective, sustainable and efficient to meet world energy needs. They grant many merits such as high-power quality, low carbon emission and minimize transmission and distribution (T\&D) losses. The DERs consist of sustainable energy sources such as tidal, biomass, wind, solar, and fuel cell. $\underline{1}$

Besides the merits of integration of DERs with the power system, the dynamic behavior of these resources is the reason for several technical challenges. These challenges include failure of protection, incorrect tripping of feeder relay, islanding operational issue, loss of coordination, fault current locator and auto recloser problems.,$\underline{2}$. The most significant challenge is known as "islanding". In islanding condition, DERs keeps on supplying power to the load, despite the isolation of the utility from the system ${ }^{4}-\underline{6}$ as demonstrated.

When the load supply from the utility grid is turned off, a virtual island is established as represented by the dotted rectangle in Figure 1. Islanding phenomena cause several complex situations such as instability of power system, poor power quality, life risks for the workers and equipment damage. To tackle the aforementioned concerns, power system standards such as IEC 62116, IEEE 929-2000, IEEE 1547-2007, AS4777.3-2005 suggested preventing stop DER operation during islanding conditions. $, \underline{,}, \underline{\underline{8}}$ IEEE 1547 standard states that islanding conditions should be recognized within 2 seconds and DERs should be isolated from the distribution network. ${ }^{9}$ For this purpose, many techniques have been established and each technique has its own favorable and unfavorable aspect. $\underline{10}$

*Author for correspondence 


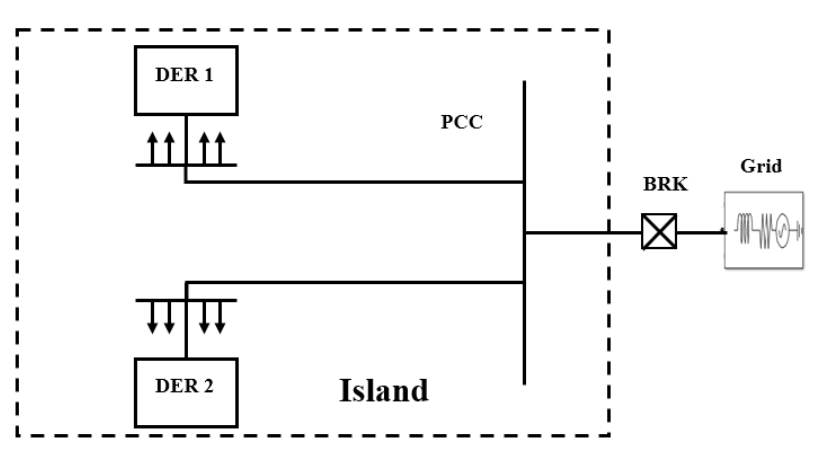

Figure 1. Islanding occurrence phenomenon.

At present, the islanding detection techniques are grouped as remote and local techniques., $, \underline{11}, \underline{12}$ The remote techniques follow the principle of communication, and this communication occurs between the utility grid and DERs. Each DER has a receiver whereas, a circuit breaker connected to the utility grid has a transmitter. Whenever the utility grid is disconnected due to any disturbance, a signal is transmitted towards DER for immediate tripping. This technique has various positive characteristics such as high reliability, rapid detection time, negligible impact on power quality and zero non-detection zones (NDZ). This technique shows remarkable performance in the case of multiple DERs $(4,10,13)$, due to is high installation and operational cost, it is not suitable for small systems. Phasor measurement unit (PMU), supervisory control and data acquisition system (SCADA), $\underline{13}$ power line carrier communication (PLCC)(13), transfer tripping scheme (TTS) and impedance insertion come under the remote islanding techniques. $\underline{14}-\underline{17}$

In local techniques, system parameters are observed at the point of common coupling (PCC) and are further classified into three main categories such as active, passive and hybrid techniques. $\frac{18}{\text { In active islanding }}$ detection method, the perturbations are fed to the system's local variables and these variables include frequency, current and voltage. $\frac{18}{}$ The impact of this perturbation will be significant for islanding scenarios otherwise it will be minute. Researchers have proposed many active islanding detection methods such as, Sandia frequency shift (SFS), $, \underline{16}, \underline{19}, \underline{0}$ reactive power export error detection (RPEED), $\underline{21}$ detection of impedance at specific frequency, $\underline{22}$ impedance measurement, $\underline{23}$ slip-mode frequency shift, $\underline{22, \underline{23}}$ active frequency drift (AFD),,$\underline{54}-\underline{26}$ Sandia voltage shift, $\underline{27}$ negative sequence current injection, $\underline{24-\underline{28}}$ high frequency signal injection, $\underline{29}, \underline{30}$ PLL perturbation and virtual capacitor. $\underline{31}$ These active detection methods are mostly used for inverter-based DERs. Active techniques decrease the non-detection zone (NDZ) and its error detection rate is also small. ${ }^{4}$ However, it needs additional equipment to inject perturbations into the system, which makes it complex. The injected perturbations further disturb the power quality of the system.

Passive islanding detection techniques are based on continuous monitoring of system parameters (voltage, frequency, active/reactive power) at point of common coupling (PCC) where utility, DER, and load are connected. The values of these parameters are analyzed with respect to a threshold value to decide either islanding has occurred or not. Passive techniques are suitable for practical implementation due to their cost-effectiveness and good power quality, but the main issue is their large NDZ. Hybrid techniques utilized the features of both passive and active techniques and present good performance with small NDZ as compare to passive techniques However, power quality issues still occur in it. Further demerits include large detection time and high cost. Voltage and real power shift, hybrid SMS and Q-f islanding techniques are examples of hybrid techniques. $. \underline{32}-\underline{34}$

\section{Discussion of Previous Work}

Passive islanding detection techniques are commonly used by utility companies due to their low cost and very small impact on power quality as compared to other detection techniques. $\underline{28}$ It has been observed that most of the passive techniques rely on any one of the following parameters to distinguish islanding events from a non-islanding eventsa such as a change in a phase shift, change in harmonic impedance, rate of change of output power, and change in frequency. $12 \underline{28}$ It is obvious that passive techniques that relied on a single parameter are less accurate and will possess a large non-detection zone (NDZ). Literature indicates that passive techniques depending on more than one parameter will be more accurate and their non-detection zone (NDZ) will also be small. It has been inferred that passive techniques based on two or more parameters are more accurate and show small NDZ in comparison to passive techniques based on a single parameter. $\underline{35}$

The change in the rate of output power and frequency, voltage unbalance and total harmonic distortion in current are an example of passive 
techniques considering more than one parameter. $\underline{36}, \underline{37}$ The use of computational intelligent-based techniques has initiated a unique aspect for passive islanding techniques. These techniques rely on many parameters which include indices and their matching rates of change. In $\underline{38}$ employed 16 parameters and all were consist of the rate of changes of selected parameters. $\operatorname{In}^{\underline{39}}$ author has worked on 2 rates of changes and 3 indices. Moreover, 21 power system parameters are examined which include the 14 indices and 7 rates of changes in..$\underline{40} \operatorname{In} \underline{41}$ has used a data mining approach for 2 rate of change and 2 indices in. The computational intelligent classifiers take these parameters (indices as well as their corresponding rate of change) as input and differentiate islanding and non-islanding scenarios.

It is observed from the empirical literature review that those techniques which rely on many parameters are more accurate, but the usage of multiple parameters make these techniques complex. Thus, upon careful analysis, the research gap observed in these techniques is the complexity due to multiple parameters. Secondly, it has been observed that no suitable method has been proposed for the selection of the appropriate parameter. Thirdly, the 16 rates of change parameters are ranked on sensitivity analysis basis in $\frac{38}{}$ but analysis of indices performance is not considered.

The main purpose of this work is to examine the features of the power system indices with respect to performance analysis, which has now been essential for the utilities along with the DER owners. This scrutiny will assist the choice of indices for detection techniques to differentiate islanding events as well as the non-islanding conditions.
The purpose of this research is to grade different power system indices. The 12 normally used power system indices are examined as per their sensitivity, under all possible islanding and the abnormal conditions. Based on the simulation results/observation, an active power-based passive technique is presented.

The study has been set in the following order: modeling of the system is discussed in section 3 whereas performance analysis of different indices is performed in section 4 . The methodology of the proposed detection technique considering the most sensitive parameter is elaborated in section 5. Simulation results, comparison with conventional technique and NDZ are discussed in sections 6, 7 and 8, respectively. Finally, the conclusion.

\section{System Modeling}

To validate the proposed technique, an $11-\mathrm{kV}$ (50 $\mathrm{Hz}$ ) distribution system is considered, consisting of a synchronous generator and wind induction generator, each having a capacity of 2.5 MVA. Two circuit breakers $\left(\mathrm{BRK}_{1}, \mathrm{BRK}_{2}\right)$ are connected to DER and utility grid respectively. IEEE 1547 standard suggests selecting a parallel RLC load to verify the performance of the presented technique. The nature of the load is a key factor in which the performance of the islanding detection technique depends. For this purpose, a three-phase parallel RLC load $\left(\mathrm{P}_{\text {Load }}=4 \mathrm{MW}, \mathrm{Q}_{\text {Load }}=2.2 \mathrm{MVar}\right)$ is connected at the point of common coupling across DERs and utility grid. MATLAB (Simulink) is used to model this system as shown in Figure 2.

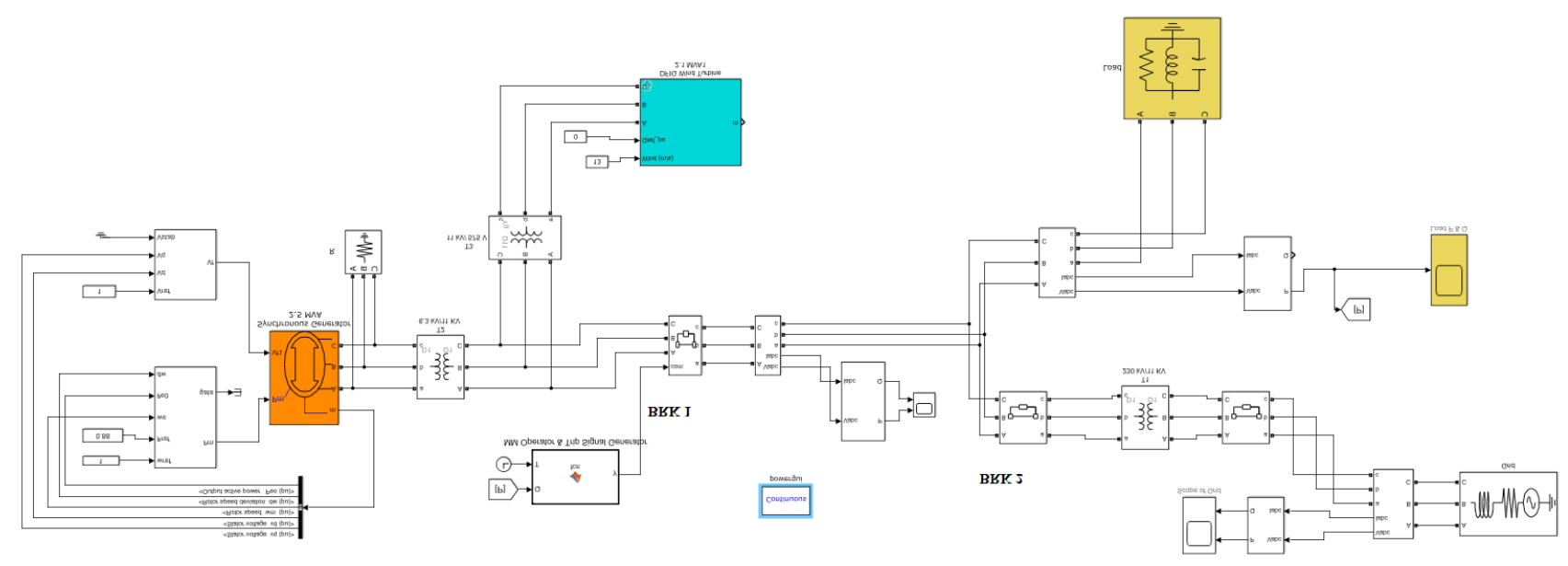

Figure 2. System under study. 
The system as shown in Figure 2 is also modelled in a standard test frame (Figure 3) according to IEEE 15472003 standard to verify the performance of the presented technique.

\section{Analysis for Sensitive Indices Selection}

Simulations were executed to check the performance analysis of power system indices such as active power $(\mathrm{P})$, reactive power $(\mathrm{R})$, voltages $(\mathrm{V})$, current $(\mathrm{I})$, and all other selected parameters normally used by researchers. Table 1 shows the detail of the selected indices.

In this work, 12 power system indices were selected and tested under different islanding and abnormal conditions like capacitor injection/ ejection, increment/ decrement of load, single and three phase faults and induction motor starting conditions at different power mismatch levels between generation and load as displayed in Table 2 .

The performance analysis of these power system indices is presented in Figure 4. All these values are taken in per unit (p.u). The P, Q, V, I, p.f, THD-V, and THD-I

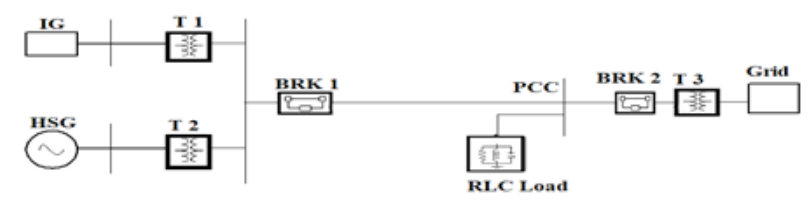

Figure 3. IEEE 1457 recommended test frame.

Table 1. Parameters (indices) used for sensitivity analysis

\begin{tabular}{|l|l|}
\hline No. & Passive parameters \\
\hline 1. & Active power $(\mathrm{P})$ \\
\hline 2. & Reactive power $(\mathrm{R})$ \\
\hline 3. & Voltage $(\mathrm{V})$ \\
\hline 4. & Current $(\mathrm{I})$ \\
\hline 5. & Power factor $(\mathrm{p} . \mathrm{f})$ \\
\hline 6. & Phase difference $(\mathrm{p} . \mathrm{d})$ \\
\hline 7. & Total harmonic distortion of voltage (THD-V) \\
\hline 8. & Total harmonic distortion of current (THD-I) \\
\hline 9. & Voltage over power factor (v/p.f) \\
\hline 10. & Voltage times power factor ( $\left(\mathrm{v}^{*} \mathrm{p} . \mathrm{f}\right)$ \\
\hline 11. & Frequency (f) \\
\hline 12. & Frequency over active power (f/P) \\
\hline
\end{tabular}

Table 2. Test cases

\begin{tabular}{|l|l|l|l|l|}
\hline \multirow{4}{*}{ Testing case } & \multicolumn{2}{|l|}{ Supply from grid } & \multicolumn{2}{l|}{ Supply from DERs } \\
\cline { 2 - 5 } & $\begin{array}{l}\mathbf{P} \\
(\text { Grid) } \\
\text { MW }\end{array}$ & $\begin{array}{l}\text { Q (Grid) } \\
\text { Mvar }\end{array}$ & $\begin{array}{l}\text { P } \\
\text { (DER) } \\
\text { MW }\end{array}$ & $\begin{array}{l}\text { Q (DER) } \\
\text { Mvar }\end{array}$ \\
\hline \multirow{5}{*}{ Islanding } & 0.5 & 0.5 & 4 & 2 \\
\cline { 2 - 5 } & 1 & 1 & 4 & 2 \\
\cline { 2 - 5 } & 1.5 & 1.5 & 4 & 2 \\
\cline { 2 - 5 } & 2 & 2 & 4 & 2 \\
\hline \multirow{5}{*}{ Faults } & 0.5 & 0.5 & 4 & 2 \\
\cline { 2 - 5 } & 1 & 1 & 4 & 2 \\
\cline { 2 - 5 } & 1.5 & 1.5 & 4 & 2 \\
\cline { 2 - 5 } & 2 & 2 & 4 & 2 \\
\hline \multirow{4}{*}{$\begin{array}{l}\text { Load } \\
\text { switching }\end{array}$} & 0.5 & 0.5 & 4 & 2 \\
\cline { 2 - 5 } & 1 & 1 & 4 & 2 \\
\cline { 2 - 5 } & 1.5 & 1.5 & 4 & 2 \\
\cline { 2 - 5 } & 2 & 2 & 4 & 2 \\
\hline \multirow{5}{*}{$\begin{array}{l}\text { Capacitor } \\
\text { switching }\end{array}$} & 0.5 & 0.5 & 4 & 2 \\
\cline { 2 - 5 } & 1 & 1 & 4 & 2 \\
\cline { 2 - 5 } & 1.5 & 1.5 & 4 & 2 \\
\cline { 2 - 5 } & 2 & 2 & 4 & 2 \\
\hline
\end{tabular}

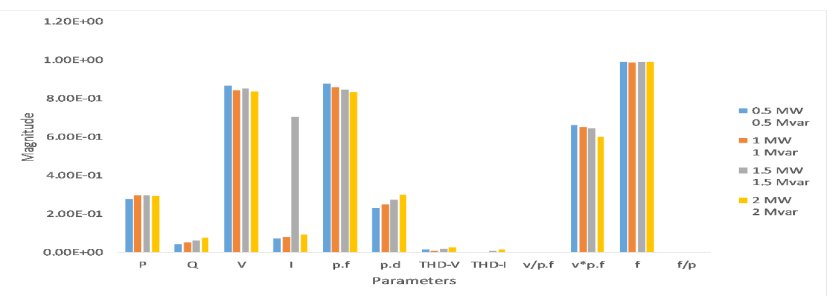

Figure 4. Islanding case.

express noteworthy changes during islanding condition as shown in Figure 4. However, it becomes difficult to distinguish between islanding and non-islanding events when these results are compared with the results of nonislanding conditions as displayed in Figures 5-10.

Among all these power system indices, only active power $(\mathrm{P})$ has expressed a remarkable difference for both islanding and non-islanding cases. Thus, active power $(\mathrm{P})$ is used for further analysis.

\section{Methodology}

After observing the performance capability of 12 distinct power system indices, it has been concluded that index active power is the most significant parameter to sense islanding. Therefore, an active power-based passive technique is recommended. The generalized procedure 


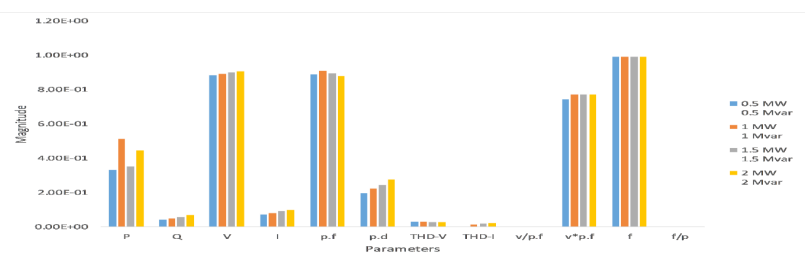

Figure 5. Capacitor switching (injection).

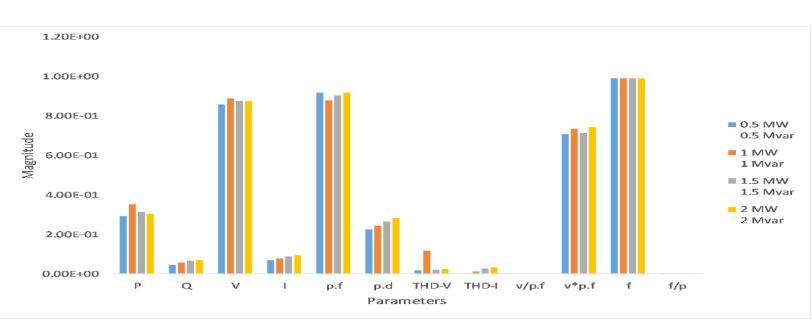

Figure 6. Capacitor switching (withdrawal).

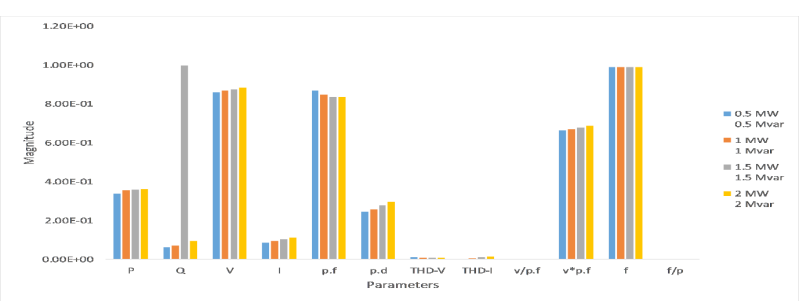

Figure 7. Load switching (increment).

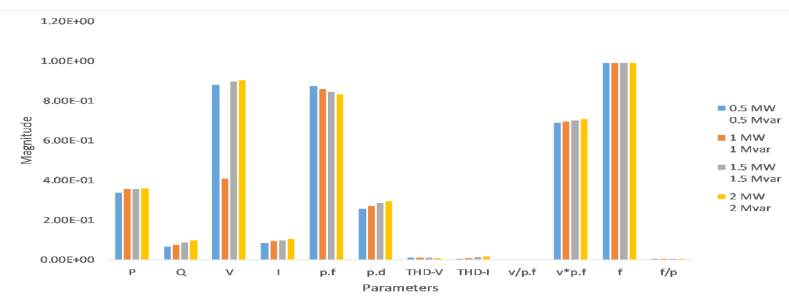

Figure 8. Load switching (decrement).

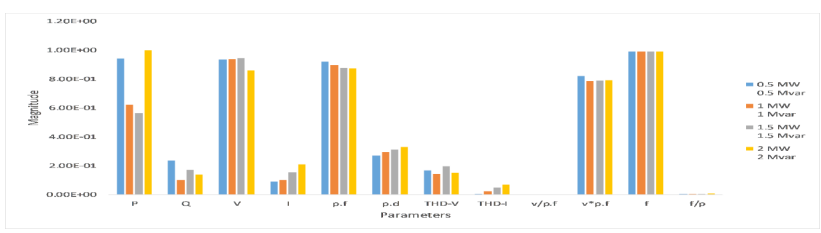

Figure 9. Single phase fault condition.

of this proposed technique is to take the mean of 5 maximum peaks of active power $\mathrm{P}$ at every 0.1 seconds. This technique starts working when Eq. (1) fulfills

$$
P_{\text {mean }}<P_{\text {threshold }}
$$

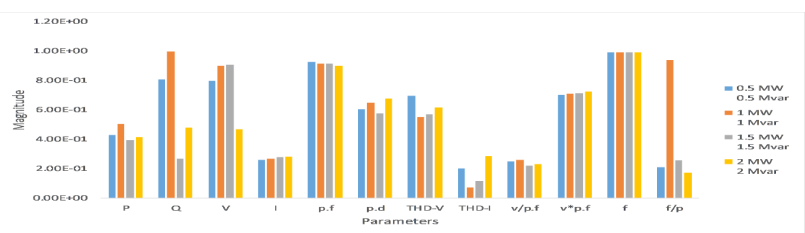

Figure 10. Three phase fault condition.

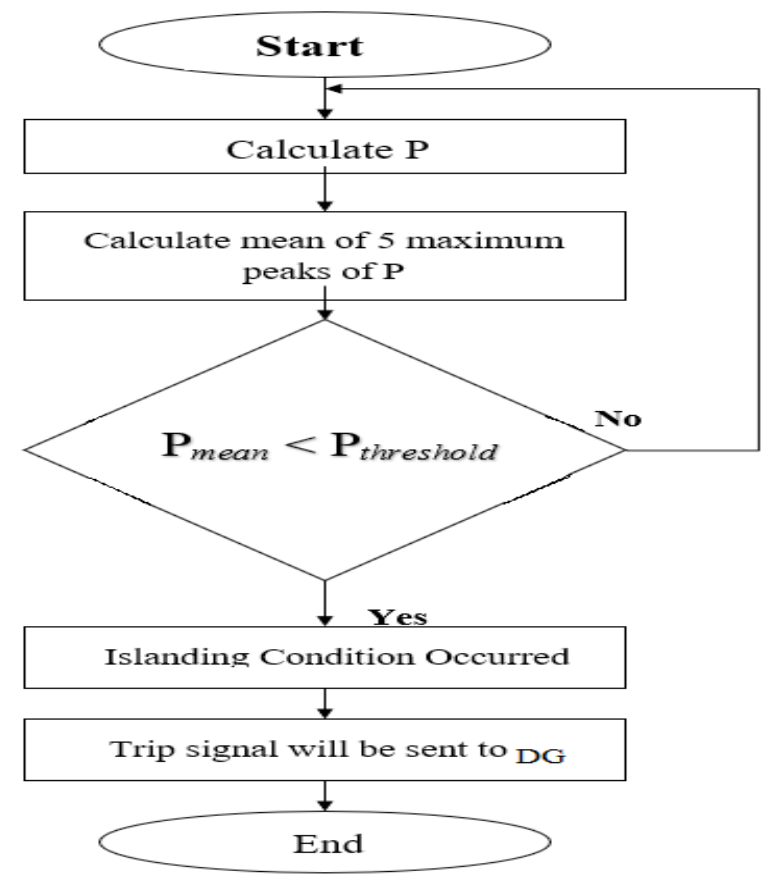

Figure 11. Proposed methodology.

where $P_{\text {threshold }}$ is the threshold value to differentiate islanding from all other non-islanding events. $P_{\text {threshold }}$ is identified from the analysis which was done in section 3. Moreover, this value is associated with specific systems, thus, it can be adjusted according to the system specification. The methodology for this technique is described in the following flow chart presented in Figure 11.

\section{Results}

The IEEE 1547 standard test system elaborated in Figure 2 is utilized to confirm the proposed islanding detection technique. All likely islanding and non-islanding scenarios are performed at 12 seconds, after the stabilization of the system. After the observation of the behavior of active power $(\mathrm{P})$ under diverse islanding and non-islanding conditions, a threshold value of $\mathrm{P}$ is selected. A selected 


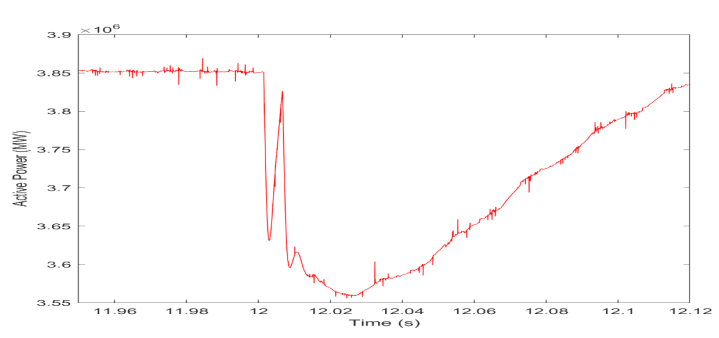

Figure 12. Close power mismatch scenario.

threshold value of $\mathrm{P}$ ( $\left.P_{\text {threshold }}\right)$ for this system is $4.8 \mathrm{MW}$. The mean of 5 highest peaks of $\mathrm{P}$ is determined during the interval 12 to 12.10 seconds.

\subsection{Islanding Under Close Mismatch Condition}

In this situation, the DERs supply power of 3.84MW and 1.31 MVar, while the utility grid is supplying trivial power of $0.031 \mathrm{MW}$ and $0.63 \mathrm{MVar}$ to energize the load of $4 \mathrm{MW}$ and 2.2 MVar.

The effect of theislanding state can be seen from Figure 12 and it has been inferred after analyzing that mean of 5 maximum peaks of $\mathrm{P}$ during 12 to 12.1 seconds interval, is $3.86 \mathrm{MW}$ which is less than a selected threshold value. So, this proposed islanding technique precisely senses the islanding under close power mismatch and sends a tripping signal to disconnect the circuit breaker of DERs.

\subsection{Islanding Under Large Mismatch Condition}

In this condition, the power mismatch between the DERs and the load is 1.0 MW and 1.0 MVar. The DERs supplies a load of 3.84 MW and 1.31 MVar, while the remaining load is energized by the utility, resulting in a total load of 4.84 MW and 2.31 MVar. The effect of the islanding state can be seen from Figure 13 and it has been inferred after analyzing that mean of 5 maximum peaks of $P$ during 12 to 12.1 seconds interval, is $4.72 \mathrm{MW}$ which is less than a selected threshold value. So, this proposed islanding technique precisely recognize the islanding under large power mismatch and sends a tripping signal to disconnect the circuit breaker of DERs.

\subsection{Load Increment and Decrement Condition}

In this event, load increment and decrement of 0.6 MW and 0.6 MVar is applied. The effect of this load

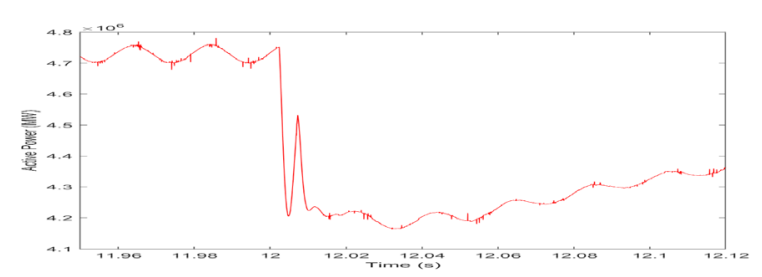

Figure 13. Large power mismatch scenario.

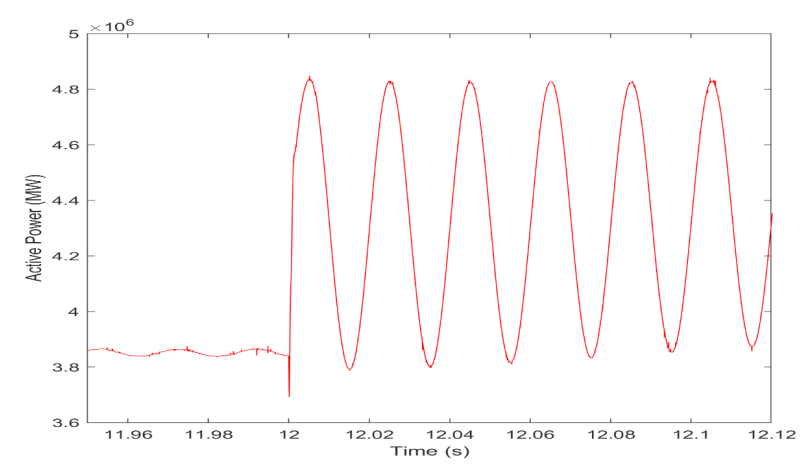

Figure 14. Load increment scenario.

increment and decrement can be observed in Figure 14 and Figure 15 respectively and it has been inferred after analyzing that mean of 5 maximum peaks of $\mathrm{P}$ during 12 to 12.1 seconds interval, for load increment is $4.85 \mathrm{MW}$ and for load decrement is $4.82 \mathrm{MW}$. These values are greater than the threshold values. So, this recommended technique will detect this situation as a non-islanding event and no trip signal will be passed to the circuit breaker of DERs, and the system will keep working normally.

\subsection{Capacitor Switching Condition}

In this scenario, injection and ejection of the capacitor bank of 0.7 MVar are applied at the system, to validate the performance of the proposed technique for leading power factor cases. The effect of capacitor bank injection and ejection can be seen from Figures 16 and 17 respectively and it has been inferred after analyzing that mean of 5 maximum peaks of $\mathrm{P}$ during 12 to 12.1 seconds interval, for capacitor bank injection is $5.40 \mathrm{MW}$ and it is $4.85 \mathrm{MW}$ for capacitor bank ejection. These values are greater than the threshold values. So, this recommended technique will detect this situation as a non-islanding event and no trip signal will be passed to the circuit breaker of DERs, and the system will keep functioning normally. 


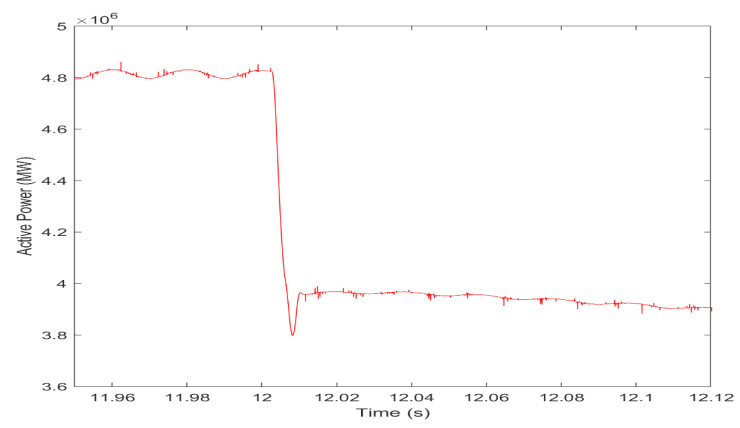

Figure 15. Load decrement scenario.

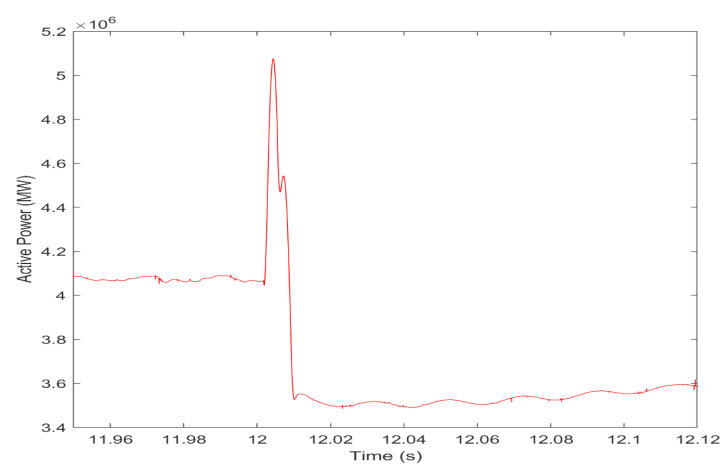

Figure 16. Capacitor injection scenario.

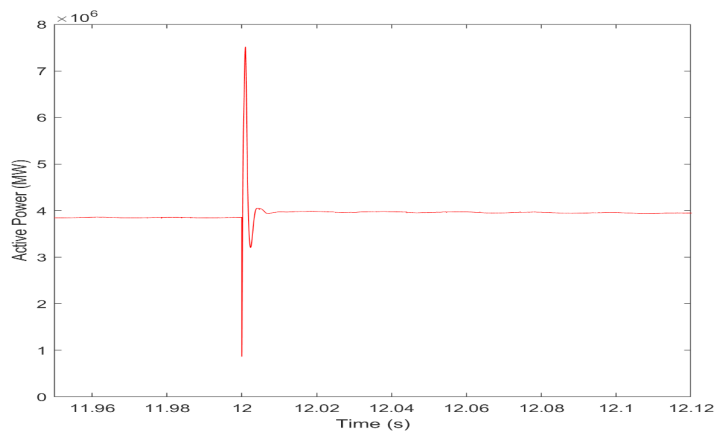

Figure 17. Capacitor ejection scenario.

\subsection{Single and Three phase Scenarios}

In this scenario, to validate the performance of the recommended technique, single and three phase faults were introduced in the system and duration for these instant faults was 0.01 second. The effect of single phase and three phase faults can be observed from Figures 18 and 19 respectively and it has been inferred after analyzing that mean of 5 maximum peaks of $\mathrm{P}$ during 12 to 12.1

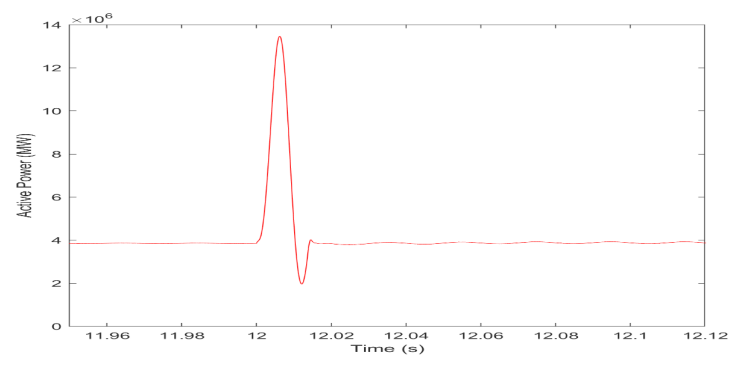

Figure 18. Single phase fault scenario.

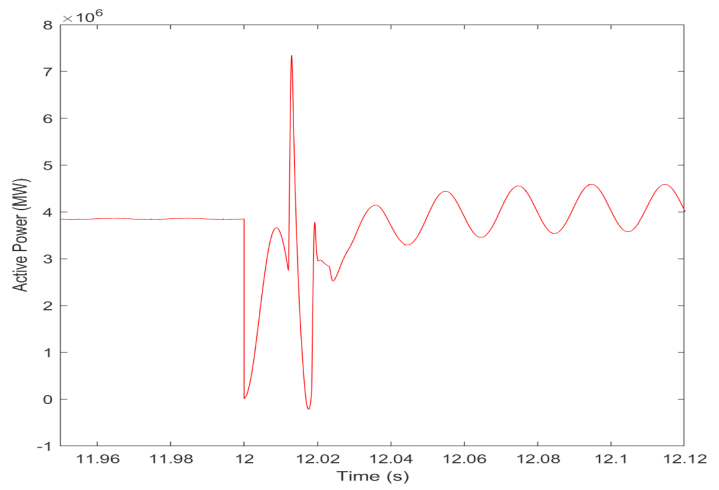

Figure 19. Three phase fault scenario.

seconds interval, for single phase the fault is $5.92 \mathrm{MW}$ and for three phase the fault is 5.13 MW.

These values are greater than the threshold values. So, this recommended technique will detect this situation as a non-islanding event and no trip signal will be passed to the circuit breaker of DERs, and the system will keep working normally.

\subsection{Induction Motor Starting}

Induction motor possesses a very low power factor in its starting, so this aspect has a severe impact on power system performance. Hence, a $50 \mathrm{hp}$ induction motor is inserted in the system to check the efficiency of the proposed technique. The impact of the insertion of induction motor in the system can be seen from Figure 20 and it has been inferred after analyzing that mean of 5 maximum peaks of $\mathrm{P}$ during 12 to 12.1 seconds interval, for the induction motor is 14.2 MW. This value is greater than the threshold value. So, this recommended technique will detect this situation as non-islanding event and no trip signal will be passed to the circuit breaker of DERs, and the system will keep working normally 


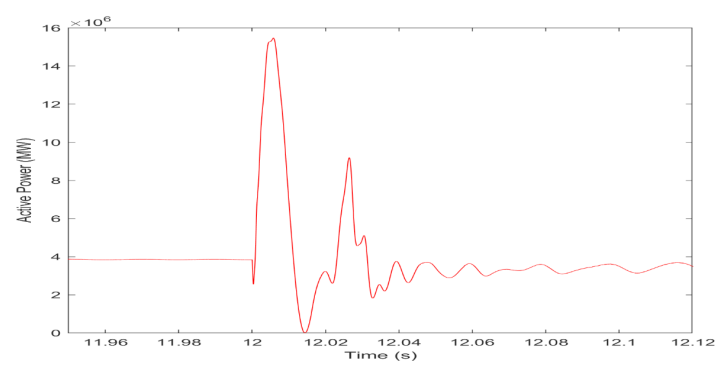

Figure 20. Induction motor start scenario.

\section{Comparison with Conventional Detection Technique}

This proposed passive technique is compared with the normally used voltage-based technique. All the simulation results for both islanding and non-islanding events are given in Table 3. It has been inferred from these results that traditionally practiced technique is unable to differentiate the islanding events from the non-islanding events appropriately for this system. Therefore, the threshold selection is quite complicated. In comparison to it, the proposed technique easily discriminates the islanding signatures from that of nonislanding signatures.

\section{Non-detection Zone (NDZ)}

NDZ is a key factor in the determination of the efficiency of an islanding technique. It is the region where the islanding technique cannot work properly. NDZ for active power is determined according to Eq. (2). $.2 \underline{42} \underline{43}$

$$
\Delta \mathrm{P}=-3 \mathrm{~V} \times \Delta \mathrm{V} \times \mathrm{I} \times \cos \varphi
$$

here, the active power imbalance is represented by $\Delta \mathrm{P}$, whereas I and $\mathrm{V}$ represent rated current and voltage, respectively. Moreover, deviation in voltage and power factor are represented by $\Delta \mathrm{V}$ and $\cos \varphi$ respectively. The highest and lowest voltage limits used for this system are 1.1 p.u and 0.9 p.u, respectively. So, for this system voltage deviation $(\Delta \mathrm{V})$ for the highest and lowest limits are 0.1 and -0.1 . The NDZ region for active power imbalance $(\triangle \mathrm{P})$ for this system is $+0.40 \mathrm{MW}$ and $-0.40 \mathrm{MW}$. For reactive power, $\mathrm{NDZ}$ is determined by Eq. (3). 42,43

$$
\Delta Q=\frac{3 V^{2}}{\omega_{n} L}\left(1-\frac{f_{n}^{2}}{\left(f_{n} \pm \Delta f\right)^{2}}\right)
$$

Table 3. Comparison of proposed technique with normally used technique

\begin{tabular}{|l|l|c|c|}
\hline Case & Scenario & $\begin{array}{c}\text { P } \\
(\mathbf{M W})\end{array}$ & $\begin{array}{c}\text { Voltage } \\
\mathbf{( k V )}\end{array}$ \\
\hline \multirow{4}{*}{ Islanding } & Close power mismatch & 3.86 & 6.20 \\
\cline { 2 - 4 } & Large power mismatch & 4.72 & 6.15 \\
\hline \multirow{4}{*}{$\begin{array}{l}\text { Non- } \\
\text { islanding }\end{array}$} & Load increment & 4.85 & 6.10 \\
\cline { 2 - 4 } & Load decrement & 4.82 & 6.30 \\
\cline { 2 - 4 } & Capacitor injection & 5.40 & 6.32 \\
\cline { 2 - 4 } & Capacitor ejection & 4.85 & 6.37 \\
\cline { 2 - 4 } & Single phase fault & 5.92 & 6.84 \\
\cline { 2 - 4 } & Three phase fault & 5.13 & 4.72 \\
\cline { 2 - 4 } & $\begin{array}{l}\text { Start of induction } \\
\text { motor }\end{array}$ & 14.2 & 4.52 \\
\cline { 2 - 4 } & \multicolumn{2}{|c}{} \\
\hline
\end{tabular}

Where, $f_{n}$ is nominal frequency and $f_{\Delta}$ is the frequency deviation and $W_{n}=2 \times \pi \times f$. The acceptable frequency deviation for this system is between $-0.5 \mathrm{~Hz}$ to $0.5 \mathrm{~Hz}$. So, NDZ for this system with respect to reactive power imbalance is 0.61 MVar and -0.63 MVar, respectively. After analyzing the simulation results, it has been inferred that this recommended technique works effectively when the active power imbalance is $0.013 \mathrm{MW}$ and reactive power imbalance is $0.60 \mathrm{MVar}$.

Thus, as compared to other conventional techniques such as Over/Under frequency and Over/Under voltage, $\underline{44}$ this recommended technique shows increased accuracy and reduced NDZ.

\section{Conclusion and Future Work}

This study presents a new passive technique based on parameter index active power (P). This index-based parameter is selected after the evaluation of twelve different indices of the power system, based on sensitivity and precision. The performance and accuracy of the recommended technique are verified and tested against the distribution system which was modelled on the IEEE 1547 standard test system for different islanding and non-islanding events. This recommended technique can differentiate islanding events from a non-islanding events at a very small power mismatch of $0.013 \mathrm{MW}$ and 0.60 MVar.

The major advantage associated with this technique is that it presents high accuracy and zero impact on power quality. These characteristics make this technique 
appropriate for real-world operation. However, the drawback of this technique is the selection of threshold value and the presence of NDZ. These issues can be overcome by employing data mining techniques, which will be considered in future work. Furthermore, the in-depth characteristics of power system indices can be further studied under signal processing based techniques.

\section{References}

1. Khamis A, Shareef H, Bizkevelci E, Khatib T. A review of islanding detection techniques for renewable distributed generation systems. Renew Sustain Energy Rev. 2013;28:483-93.

2. Rehmani MH, Reisslein M, Rachedi A, Erol-Kantarci M, Radenkovic M. Integrating renewable energy resources into the smart grid: recent developments in information and communication technologies. IEEE Trans Ind Inform. 2018;14(7):2814-25.

3. Chahyal DM, Kalgunde MN, Kalage AA. A study on protection issues in presence of distributed generation. International conference on algorithms, methodology, models and applications in emerging technologies (ICAMMAET); 2017. P. 1-4.

4. Raza S, Mokhlis H, Arof H, Laghari JA, Wang L. Application of signal processing techniques for islanding detection of distributed generation in distribution network: a review. Energy Convers Manag. 2015;96:613-24.

5. Raghav LP, Sandhya T. An active frequency drift method for an islanding detection of grid connected microturbine generation system. Int J Innov Res Sci Eng Technol. 2014;3(1):111-5.

6. Telukunta V, Pradhan J, Agrawal A, Singh M, Srivani SG. Protection challenges under bulk penetration of renewable energy resources in power systems: a review. CSEE J Power Energy Syst. 2018;3(4):365-79.

7. Ku Ahmad KNE, Selvaraj J, Rahim NA. A review of the islanding detection methods in grid-connected PV inverters. Renew Sustain Energy Rev. 2013;21:756-66.

8. Zeineldin HH, Abdel-Galil T, El-Saadany EF, Salama MMA. Islanding detection of grid connected distributed generators using TLS-ESPRIT. Electr Power Syst Res. 2007;77, (2):155-62.

9. Khamis $\mathrm{A}, \mathrm{Xu} \mathrm{Y}$, Mohamed A. Comparative study in determining features extraction for islanding detection using data mining technique: correlation and coefficient analysis. Int J Electr Comp Eng. 2017;7(3):1112-24.

10. Hatata FAY, Abd-Raboh EH, Sedhom BE. A review of antiislanding protection methods for renewable distributed generation systems. J Electr Eng. 2016;16(1):235-46.
11. Nadia A, Salam A. Performance of multiple passive islanding detection technique for synchronous type of DG. J Electr Syst. 2017;13(3):568-78.

12. Reddy CR, Reddy KH. Islanding detection techniques for grid integrated distributed generation - a review. Int J Renew Energy Res. 2019;9(2):1-18.

13. Xu W, Zhang G, Li C, Wang W, Wang G, Kliber J. A power line signaling based technique for anti-islanding protection of distributed generators - part I: scheme and analysis. IEEE Trans Power Deliv. 2007;22(3):1758-66.

14. Barrett J, Redfern M. A new microprocessor based islanding protection algorithm for dispersed storage and generation units. IEEE Trans Power Deliv. 1995;10(3):1249-54.

15. Comparison and review of islanding detection techniques for distributed energy resources. [cited 2008 Oct]. https://www.researchgate.net/publication/224611487_ Comparison_and_review_of_islanding_detection_ techniques_for_distributed_energy_resources.

16. Evaluation of islanding detection methods for photovoltaic utility. [cited 2002]. http://www.ieapvps.org/index. php?id=9\&eID=dam_frontend_push\&docID=386.

17. Usman MU, Faruque MO. Applications of synchrophasor technologies in power systems. J Mod Power Syst Clean Energy. 2019;7(2):211-26.

18. Islanding detection technique based on rate of change of reactive power (dq/dt). [cited 2018 Jan]. https://www. researchgate.net/publication/330813745_Islanding_ detection_technique_based_on_rate_of_change_of_ reactive_power_dqdt.

19. Wang X, Freitas W, Xu W. Dynamic non-detection zones of positive feedback anti-islanding methods for inverterbased distributed generators. IEEE Trans Power Deliv. 2011;26(2):1145-55.

20. Lopes LAC, Sun H. Performance assessment of active frequency drifting islanding detection methods. IEEE Trans Energy Convers. 2006;21(1):171-80.

21. Moeini A, Darabi A, Rafiei SMR, Karimi M. Intelligent islanding detection of a synchronous distributed generation using governor signal clustering. Electr Power Syst Res. 2011;81(2):608-16.

22. Singam B, Hui LY. Assessing SMS and PJD schemes of antiislanding with varying quality factor. In: IEEE international power and energy conference 2006 PECon; 2006. P. 196- 201.

23. Mohamad H, Mokhlis H, Bakar AHA, Ping HW. A review on islanding operation and control for distribution network connected with small hydro power plant. Renew Sustain Energy Rev. 2011;15(8):3952-62.

24. Du P, Ye Z, Aponte EE, Nelson JK, Fan L. Positive-feedbackbased active anti-islanding schemes for inverter-based distributed generators: Basic principle, design guideline 
and performance analysis. IEEE Trans Power Electron. 2010;25(12):2941-48.

25. Liu F, Kang Y, Zhang Y, Duan S, Lin X. Improved SMS islanding detection method for grid-connected converters. IET Renew Power Gener. 2010;4(1):36.

26. Yafaoui A, Wu B, Kouro S. Improved active frequency drift anti-islanding detection method for grid connected photovoltaic systems. IEEE Trans Power Electron. 2012;27(5):2367-75.

27. Wang X, Freitas W, Xu W, Dinavahi V. Impact of interface controls on the steady-state stability of inverter-based distributed generators. In: 2007 IEEE Power Eng Soc Gen Meet PES; 2007.P. 1-4.

28. Karimi H, Yazdani A, Iravani R. Negative-sequence current injection for fast islanding detection of a distributed resource unit. IEEE Trans Power Electron. 2008;23(1):298-307.

29. Emadi A, Afrakhte H, Sadeh J. Fast active islanding detection method based on second harmonic drifting for inverter-based distributed generation. IET Gener Transm Distrib. 2016;10(14):3470-80.

30. Reigosa D, Briz F, Blanco C, Garc P, Guerrero JM. Active islanding detection for multiple generators using highfrequency signal injection. IEEE Energy Convers Cong Expo (ECCE). 2014;29(3):1192-99.

31. Chiang WJ, Jou HL, Wu JC. Active islanding detection method for inverter-based distribution generation power system. Int J Electr Power Energy Syst. 2012;42(1):158-166.

32. Chang W. A hybrid islanding detection method for distributed synchronous generators. Int Power Electron Conf ECCE ASIA. 2010;499:1326-30.

33. Mishra M, Rout PK. Time-frequency analysis based approach to islanding detection in micro-grid system. Int Rev Electr Eng. 2016;11(1):116-28.

34. Laghari JA, Mokhlis H, Bakar AHA, Karimi M. A new islanding detection technique for multiple mini hydro based on rate of change of reactive power and load connecting strategy. Energy Convers Manag. 2013;76:215-24.

35. An improved islanding detection technique and priority based load shedding for distribution system with multiple
DGs. [cited 2016 Dec 19]. https://ieeexplore.ieee.org/ document/7858886.

36. Li C, Cao C, Cao Y, Kuang Y, Zeng L, Fang B. A review of islanding detection methods for microgrid. Renew Sustain Energy Rev. 2014;35:211-20.

37. Balaguer-Álvarez IJ, Ortiz-Rivera EI. Survey of distributed generation islanding detection methods. IEEE Lat Am Trans. 2010;8(5):565-70.

38. A new islanding detection technique for mini hydro generation based on the evaluation of different power system parameters. [cited 2015 Dec]. https://www.researchgate. net/publication/326768318_A_new_islanding_Detection_ Technique_for_Mini_Hydro_Generation_based_on_the evaluation_of_Different_Power_System_Parameters.

39. Alam MR, Muttaqi KM, Bouzerdoum A. An approach for assessing the effectiveness of multiple-feature-based SVM method for islanding detection of distributed generation. IEEE Trans Ind Appl. 2014;50(4):2844-52.

40. Faqhruldin ON, F. El-saadany E, Zeineldin HH. A universal islanding detection technique for distributed generation using pattern recognition. IEEE Trans Smart Grid. 2014;5(4):1985-92.

41. El-Arroudi K, Joós G. Data mining approach to threshold settings of islanding relays in distributed generation. IEEE Trans Power Syst. 2007;22(3):1112- 19.

42. Zeineldin H, El-Saadany EF, Salama MMA. Impact of DG interface control on islanding detection. IEEE Power Energy Soc Gen Meet. 2005. 2005;2(3):1489-95.

43. Hashemi F, Ghadimi N, Sobhani B. Islanding detection for inverter-based DG coupled with using an adaptive neurofuzzy inference system. Int J Electr Power Energy Syst. 2013;45(1):443-55.

44. Laghari JA, Mokhlis H, Karimi M, Bakar AHA, Mohamad H. An islanding detection strategy for distribution network connected with hybrid DG resources. Renew Sustain Energy Rev. 2015;45:662-76. 